\title{
TATA KOTA MOHENJODARO
}

\author{
Nisa Sabrina Geldin Gerung \\ nisasgg.education@gmail.com \\ Mahasiswa Pendidikan Sejarah \\ Universitas Sultan Ageng Tirtayasa \\ November 2017
}

\section{PENDAHULUAN}

Kebudayaan lembah sungai Indus atau Kebudayaan Harappa merupakan salah satu kebudayaan tertua di dunia. Kebudayaan Mohenjodaro sendiri termasuk ke dalam kebudayaan Harappa. Mohenjodaro adalah kota yang dibangun sekitar tahun 2600 SM di lembah sungai Indus, Provinsi Sindh, Pakistan. Terletak di 25 km barat daya Kota Larkana. Ditemukan tahun 1922 oleh arkeolog, Sir John Marshall dan dilakukan ekskapasi lebih dalam oleh Ahmad Hasan Dani dan Mortimer Wheeler pada tahun 1945.

Mohenjodaro terkenal dengan tata kotanya yang terencana dan matematis. Makalah ini terdiri dari dua topik masalah yaitu Geohistoris Mohenjodaro dan topik utama yaitu Tata Kota Mohenjodaro. Geohistoris mencangkup Istilah, Bahasa, Pembagian Wilayah, Penduduk, Kepercayaan dianut dan Sumber Sejarah. Sedangkan topik Tata Kota membahas distrik kota beserta komponenkomponennya. Tujuan pembuatan makalah ini yaitu untuk mendeskripsikan poinpoin terkait tata kota Mohenjodaro beserta komponen dan geohistorisnya.

Dari pembahasan ini kita dapat mengkaitkan dan membandingkan kebudayaan Mohenjodaro dengan kebudyaaan manusia saat ini. Sehingga kita dapat mengevaluasi lebih lanjut kebudayaan manusia jaman sekarang. 


\section{PEMBAHASAN}

Para peneliti biasa menyebut kota terbesar di lembah sungai Indus ini dengan sebutan Mohenjodaro. Dalam bahasa Indonesia Mohenjodaro berarti "bukit orang mati". Nama aslinya sampai sekarang belum diketahui. Sumber Sejarahnya yaitu berbagai hasil-hasil kebudayaan peradaban seperti reruntuhan kota, mainan dari terakota, patung, dan masih banyak lagi.

Penduduk aslinya yaitu penduduk berbahasa Dravida termasuk dalam ras Austroloid yang berciri fisik berbadan tegap, pendek, bibir tebal, hidung pesek, rambut ikal, dan kulit hitam. Barangkali tak kurang dari 40.000 penduduk tinggal di kota mohenjodaro. Kepercayaan yang dianut adalah agama keibuan atau Mother Goddes semacam tokoh ibu pertiwi yang banyak dipuja oleh orang di daerah Asia kecil. Hal ini berdasarkan penemuan lukisan kecil pada periuk belanga serta materai maupun jimat-jimat.

Pada dasarnya tata kota Mohenjodaro dapat dikelompokan menjadi dua distrik yaitu, Baluarti (Citadel) dan kota/pemukiman (Lower Town). Baluarti atau biasa disebut Citadel merupakan pusat pemerintahan kota yang terletak di atas gundukan barat laut lokasi reruntuhan. Penghuninya adalah raja dan pimpinanpimpinan beserta keluargnya. Baluarti terdiri dari beberapa bangunan yaitu sebuah lumbung gandum raksasa (The Granary), bangsal pertemuan upacara (Assembelly Halls), dan sebuah pemandian umum (Greet Bath) yang barangkali digunakan untuk upacara agama.

Dibawahnya terhamparlah kota dalam pola kisi-kisi matematika ketat dengan ciri khas kotanya yaitu jalan pararel yang memanjang dengan lurus dan lebar. Jalan tersebut terbentang dari timur ke barat dan dari utara ke selatan saling berpotongan dengan sudut siku-siku. Variasi lebarnya 9 hingga 34 kaki dan memanjang lebih dari setengah mil. Terdapat terotoar selebar $1 / 2 \mathrm{~m}$ yang mengapit kanan kiri jalan.

Pada kota ini terdapat bangunan rumah, restoran, toko pengrajin tembikar, pandai besi, pengrajin hiasan kerang, dan pengrajin manik-manik.bangunanbangunan tersebut dibuat berkomplek-komplek dengan mengadopsi pola tata 
bangunan grid atau kotak-kotak.Antar distrik dibatasi oleh pagar tinggi besar yang memiliki menara dan juga system saluran air bawah tanah.

Karaketeristik dari rumah-rumah di Mohenjodaro ialah bahan dasarnya terbuat dari batu bata lumpur dan batu bata kayu. Dinding-dinding rumahnya yang tidak berjendela dibuat langsung menghadap ke jalanan. Sedangkan pintu masuk rumah terdapat di dalam lorong-lorong sempit di belakang jalan utama. Rumahnya sendiri kebanyakan berjenis rumah satu lantai (lantai dasar saja) dan dua lantai. Selain itu terdapat sekelompok barak seperti rumah petak sempit yang digunakan untuk tempat tinggal orang-orang berstatus ekonomi rendah.
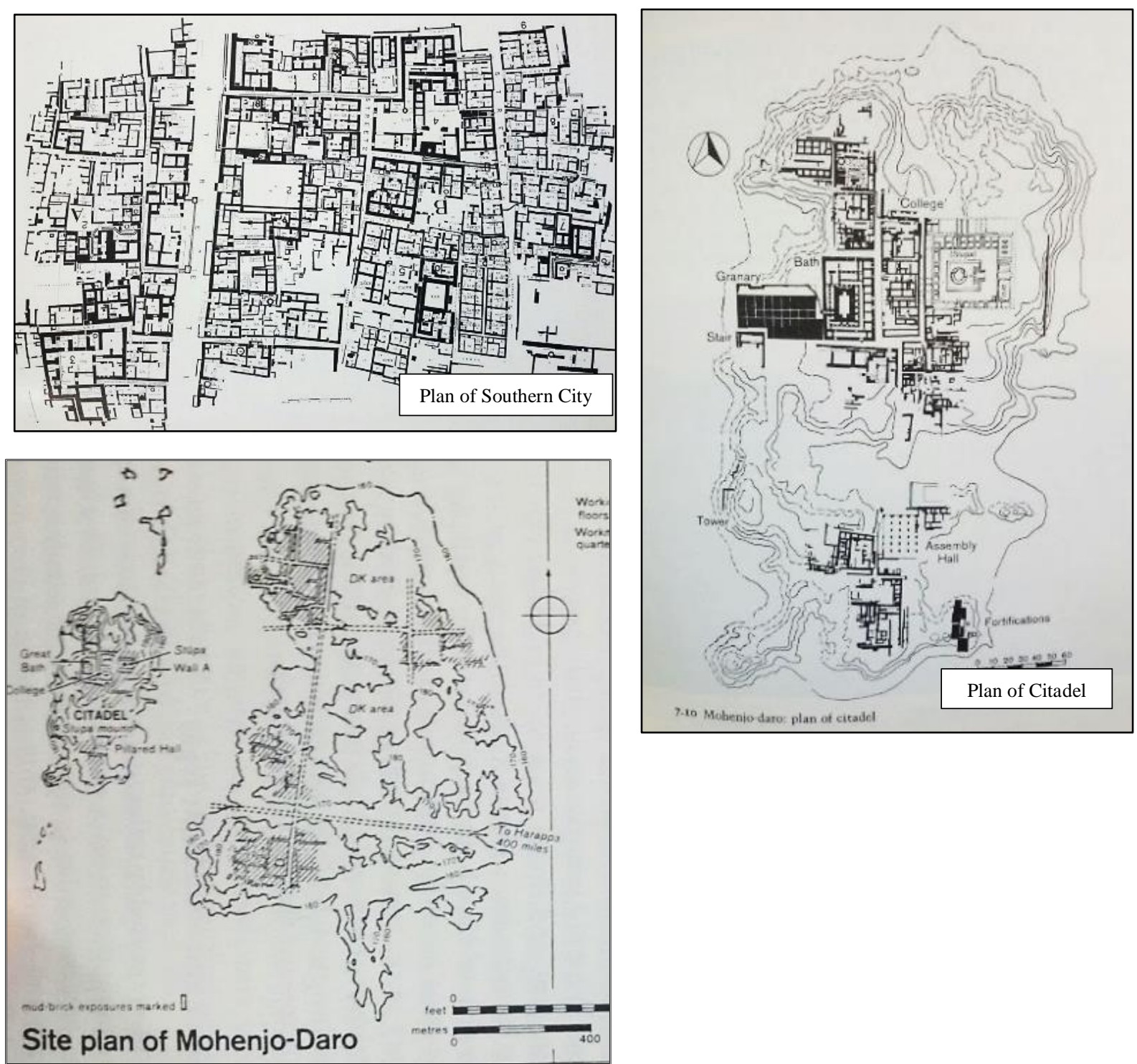


\section{PENUTUP}

Berkaitan dengan teori Challenge and Response yang dikemukakan oleh Arnold Joseph Toynbee mengatakan bahwa suatu peradaban disekitar sungai selalu dihadapkan pada tantangan alam (challenge). Dari letak geografisnya yaitu hulu sungai Indus dapat kita ketahui bahwa kota tersebut sering terjadi bencana banjir. Membuat kota ini dibangun berulang kali dan penduduknya dipaksa mengevaluasi tata kotanya sedemikian rupa. Keberhasilan mereka dalam menghadapi tantangan itulah sebabnya kota ini terbilang maju pada jamannya

\section{DAFTAR PUSTAKA}

Adams, Simon. 2004. Sejarah Dunia. Erlangga: Jakarta.

Aizid, Rizam. 2014. Peradaban-Peradaban Besar Dunia. Laksana: Jogjakarta.

Allchin, Raymond. 1982. The Rise of Civilazition in India and Pakistan. Press Cyndicate of the University of Cambridge: Cambridge.

Gabriel, Angeli. 2017. Mohenjo Daro 101 National Geographic. [Online] https://www.youtube.com/watch? $v=Q U n g-i H h S z U$. Diakses 8 Oktober 2017.

Gokhale, B. 1952. Ancient India (History and Culture). Asia Publishing House: Bombay.

Kirkpatrick, Naida. 2002. The Indus Valley. [Online] http://www.worldlibrary.org/articles/eng/Harappan_architecture. Diakses 8 Oktober 2017.

Malvini, Agustina, dkk,. 2008. World Heritage Nature \& Culture Under The Protection of UNESCO (Asia Tengah dan Asia Selatan). Batara Publishing: Jakarta.

Sadasivan, Balaji. 2011. The Dancing Girl - A History of Early India. ISEAS Publising: Pasir Panjang.

Su'ud, Abu. 1988. Memahami Sejarah Bangsa-Bangsa Asia Selatan. Kemdikbud: Jakarta.

Schulberg, Lucille. 1983. India Yang Bersejarah. Tira Pustaka: Jakarta. 